\title{
PROGRAM CERDAS PENGHIJAUAN DENGAN Casuarina equisetifolia DI PANTAI PARUPUK TABING KOTA PADANG
}

\author{
THE SMART PROGRAM OF REVEGETATION WITH Casuarina equisetifolia AT \\ PARUPUK TABING BEACH, PADANG CITY
}

\author{
${ }^{1)}$ Jamilah*, ${ }^{2)}$ Isril Berd, ${ }^{3)}$ Junaidi, ${ }^{4)}$ Zuherna Mizwar, ${ }^{5)}$ Erwin, ${ }^{6}$ Nursidah \\ ${ }^{1)}$ Fakultas Pertanian Universitas Tamansiswa Padang \\ ${ }^{2)}$ Keteknikan Pertanian Fakultas Pertanian Universitas Andalas \\ ${ }^{3)}$ Ilmu Perikanan Universitas Bung Hatta \\ ${ }^{4)}$ Forum DAS Kota Padang \\ ${ }^{5)}$ BPDASHL Agam Kuantan \\ J1. Tamansiswa No. 9 Padang, Sumatera Barat 25138; kampus Limau Manis Kecamatan Pauh Kota \\ Padang; Kampus Bung Hatta Ulak Karang Padang; Kantor BPDASHL Agam Kuantan Jl. Khatib \\ Sulaiman Kota Padang, Sumatera Barat. Kode pos 27361. \\ *Email: jamilahfatika@gmail.com
}

\begin{abstract}
ABSTRAK
Kegiatan penghjauan di Pantai Parupuk Tabing Kota Padang merupakan suatu keharusan dan menjadi tanggung jawab semua fihak. Hal ini karena kondisi pantai yang sangat tandus, dan mengkhawatirkan adanya isu tsunami yang akan membahayakan secara langsung masyarakat yang ada ditepi pantai. Saat ini pemerintah Kota Padang sudah membangun crip pemecah ombak dengan menumpuk secara teratur batu coral menjorok ke laut yang berguna memecah ombak. Namun jika ada bencana gempa yang besar, hal ini dianggap akan membahayakan. Oleh sebab itu penghijauan pantai menggunakan tanaman casuarina equisetifolia menjadi laternatif yang paling aman. Masyarakat digandeng bersama dalam upaya menghijuakan pantai, baik dalam kegiatan menyulam tanaman yang mati atau juga memelihara tanaman yang tumbuh. Dari kegiatan memberikan edukasi kepada masyarakat pantai upaya pemeliharaan tanaman yang baik, mampu menurunkan angka kematian tanaman dari $30 \%$ menjadi 5\% saja. Kegiatan ini dilakukan dengan penyuluhan kepada masyarakat agar mampu memelihara lingkungan khususnya menjaga tanaman yang tumbuh agar tepi pantai terpelihara tetap hijau. Selain itu, diharapkan pantai tidak mudah tergerus ombak. Kesimpulan kegiatan penghijauan pantai Parupuk Tabing dengan menggunakan tanaman Casurina sangat efektif dalam memelihara pantai dari kekeringan dan kegersangan. Upaya tersebut menjadi sangat besar maknanya karena ada komitmen bersama antara masyarakat sekitar yang mendapat manfaat dari penghijauan tersebut. Kerjasama dengan masyarakat mencegah banyaknya tanaman yang mati akibat kekeringan.
\end{abstract}

Kata kunci: Casuarina Equisetifolia; Penghijauan; Pantai Parupuk Tabing

\section{ABSTRACT}

Green activities at the Padang City Tabing Parupuk Beach are a must and are the responsibility of all parties. This is because the condition of the coast is very barren, and it is worrying that there is a tsunami issue that will directly endanger the people who live on the coast. Currently, the Padang City government has built wave-breaking crypts by regularly piling up coral rocks jutting into the sea that is useful for breaking the waves. But if there is a large earthquake, this is considered to be dangerous. Therefore beach greening using Casuarina equisetifolia plants is the safest alternative. The community collaborated within the effort to green the beach both in embroidering dead plants or also maintaining growing plants. From the activities of providing education to coastal communities, good crop maintenance efforts can reduce plant mortality from $2030 \%$ to 5\%. This activity is carried out with counseling to the community to be able to preserve the environment, especially maintaining plants 
that grow so that the waterfront is kept green. Besides that, the beach is not easily crushed by the waves. Conclusion Parupuk Tabing beach greening activities using Casurina plants are very effective in maintaining the beach from drought and aridity. The effort has a very big meaning because there is a shared commitment between the surrounding community that benefits from the afforestation. Collaboration with the community prevents many plants that die from drought.

Keywords: Casuarina Equisetifolia; Greening; Parupuk Tabing Beach

Submitted : 7 Desember 2019 Revision : 31 Agustus 2020 Accepted : 6 September 2020

\section{PENDAHULUAN}

Pantai Parupuk Tabing, merupakan salah satu pantai yang berada di Kota Padang, dan mengalami ketandusan, serta belum diberdayakan sebagai objek wisata. Menurut masyarakat di kelurahan Parupuk Tabing, pantai tersebut sudah pernah dicoba dihijaukan hingga 20 kali oleh instansi dan kelompok-kelompok pecinta alam lainnya, namun selalu gagal. Maka Forum Daerah Aliran Sungai (DAS) Kota Padang, Balai Pengelolaan Daerah Aliran Sungai Hutan Lindung (BPDASHL) Agam Kuantan, beberapa Perguruan Tinggi bersama masyarakat sekitar mencoba memulai melakukan penghijauan kembali dengan menggunakan tanaman cemara laut atau cemara Udang (Casuarina equisetifolia). Haryadi (2015) menyatakan bahwa cemara laut merupakan jenis tanaman khas pantai yang potensial untuk rehabilitasi lahan dan konservasi tanah (RLKT) pantai berpasir. Jenis ini mampu menahan angin laut dan uap air laut yang mengandung garam, sehingga mampu mendorong perbaikan lingkungan.

Pentingnya melakukan penghijauan di sekitar pantai, selain mencegah angin yang terlalu kuat saat badai, yang dapat merusak hunian sekitar pantai, juga mencegah efek gelombang yang mengabrasi bibir pantai, sebagai barrier bagi tsunami serta dapat dijadikan sebagai obyek wisata pantai yang teduh. Menurut Haryadi (2015) rehabilitasi menggunakan cemara laut atau cemara udang, lahan pantai berpasir yang semula gersang dan tidak dimanfaatkan, dapat meningkat produktivitasnya sehingga mendatangkan keuntungan bagi masyarakat. Jika kawasan tersebut hijau dan masyarakat dapat menikmati indahnya alam pantai, dan masyarakat dapat mengembangkan bisnis kuliner yang merupakan ciri khas Sumatera Barat. Oleh sebab itu pemberdayaan masyarakat melalui kegiatan penghijauan ini sangat penting, mengingat bahwa setiap tanaman yang ditanam akan memberikan faedah yang luas bagi lingkungan.

Cemara laut (Casuarina equisetifolia) merupakan tanaman dengan banyak manfaat (multi purpose). Sebagai tanaman hias, tanaman ini memiliki nilai ekonomi dan estetika yang tinggi. Selain itu, tanaman ini merupakan tanaman yang potensial untuk dikembangkan dalam upaya konservasi kawasan pesisir, sebagai penahan angin dan abrasi air laut seperti di kawasan konservasi Taman Wisata Pantai Panjang Bengkulu. Umumnya cemara laut berkembang biak secara generatif menggunakan biji. Biji berukuran sangat kecil dan dibungkus oleh selaput tipis, sehingga mudah diterbangkan oleh angin. Biji cemara laut memiliki embrio dengan daya kecambah yang rendah. Sangat penting untuk dilakukan upaya penyelamatan embrio cemara laut agar dapat tumbuh dan berkembang sehingga mampu melestarikan kawasan konservasi 
Taman Wisata Pantai Panjang di Bengkulu khususnya, kawasan pesisir secara nasional umumnya (Marlin et al., 2010).

Casuarina merupakan suatu jenis pohon tergolong kayu-kayuan yang bersifat serbaguna atau multi purpose tree species yang memiliki bakteri di akarnya mampu memfiksasi N2 udara. Spesies yang tergolong multi purpose tree tersebut dapat memenuhi lebih dari satu manfaat (fungsi) pada suatu areal. Manfaat yang serbaguna tersebut maka tanaman ini sangat banyak dikembangkan khususnya pada kawasan pantai dan kawasan marginal lainnya. Tanaman ini juga sangat adaptif terhadap lingkungan buruk. Oleh sebab itu masyarakat menyukai pemanfaatan tanaman tersebut untuk ditanaman di lahan yang sulit tersedia air. Anonim (2013) menjelaskan bahwa ada manfaat yang besar bagi petani. Manfaat utama jenis ini berupa kayu yang sangat tinggi kualitasnya sebagai bahan bakar (arang), kayu gelondongan untuk pancang, tonggak dan pagar. Sesuai Casuarina mempunyai potensi yang baik seebagai bahan kayu bakar terbaik di dunia.

Keunggulan tanaman Casuarina adalah bisa tumbuh di lahan marginal karena tanaman ini memiliki akar yang diinfeksi oleh Actimycetes (bakteri benang) dengan nama Frankia. Frankia mampu melakukan fiksasi N2 dari udara lalu tanaman inang mendapatkan manfaat $\mathrm{N}$ tersebut dari hasil kerja Frankia. Hasil serasah yang berguguran di tanaman cemara laut ini cukup tinggi dan dapat menyuburkan tanah. Pada periode 8,5 tahun, hutan yang ditanami secara monokultur Eucalyptus ataupun campuran antara cemara laut dengan lamtoro (Leucaena leucocephala) (50:50) menunjukkan bahwa produk serasah sebesar $3 \mathrm{Mg}$ ha-1 pada Eucalyptus monocul-ture menjadi $124 \mathrm{Mg}$ ha-1 pada campuran the Casuarina/Leucaena. Produk guguran daun dan pengembalian hara $\mathrm{N}, \mathrm{P}, \mathrm{K}, \mathrm{Ca}$, dan $\mathrm{Mg}$ umumnya lebih tinggi pada tanaman Leucaena, sedang untuk Casuarina dan sangat rendah pada Eucalyptus. Keunggulan lainnya adalah spesies kayu-kayuan lain yang tumbuh di bawah tegakan Casuarina lebih banyak dibandingkan di bawah tegakan Eucalyptus atau campuran Eucalyptus/ Leucaena (Ogunwande et al., 2011).

Tanaman Casuarina memberikan sumbangan kesejukan, oksigen, datangnya burung-burung liar, sehingga menambah indahnya suasana di lingkungan tersebut. Tanaman yang tumbuh di tepi pantai juga sebagai reservoar air tawar bagi lingkungan sekitar, sehingga mampu menahan intrusi air laut masuk lebih jauh ke daratan. Tanaman kayu berperan sebagai reservoar air yang mampu menyediakan air tawar di kala saat musim kemarau dan penahan banjir saat musim hujan (Nugroho \& Sumardi, 2010). Tujuan kegiatan memberikan edukasi bagi masyarakat sekitar pantai Parupuk Tabing Kota Padang untuk menghijaukan pantai yang tandus dengan menggunakan tanaman Casuarina equisetifolia.

\section{METODE}

Kegiatan pengabdian dilakukan di pantai Parupuk Tabing, Kota Padang. Peserta adalah kelompok masyarakat nelayan Pantai Parupuk yang berjumlah 20 orang. Kegiatan diawali dengan sosialisasi kegiatan penanaman dan mengajak masyarakat agar bersedia menanam sebanyak 200 batang tanaman cemara Casuarina di tepi pantai. Casuarina dipilih karena dianggap cocok dan mampu bertahan pada lahan pantai yang gersang dan kekurangan unsur hara tersebut. Bibit cemara dan semua kebutuhan lainnya yang berhubungan dengan tanaman sudah disiapkan oleh BPDASHL Agam Kuantan. Bibit cemara yang digunakan bermacammacam antara lain cemara udang, cemara laut dan alat pemeliharaan lainnya seperti pada Gambar 1, dan bibit mati dilakukan 
penyulaman dengan bibit yang sudah disiapkan dari pembibitan BPDASHL Agam Kuantan.

Bahan lain yang digunakan adalah kayu ajir, pupuk kandang, tali pengikat, sabut kelapa, bola-bola air yang terbuat dari kantung plastik isi $2 \mathrm{~kg}$ yang dipenuhi air lalu diikat kuat, kemudian ditusuk jarum halus dan diletakkan posisi lubang menghadap ke atas.
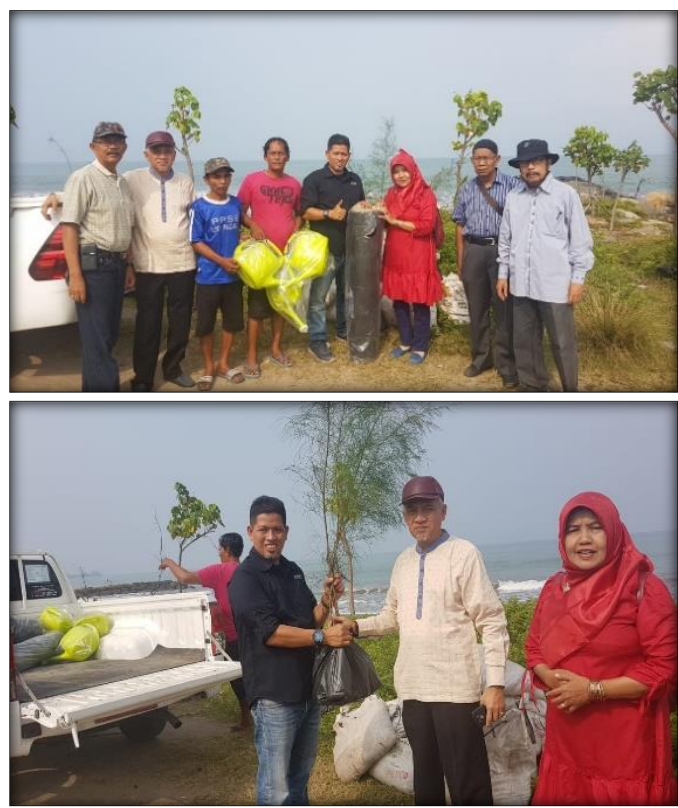

Gambar 1. Penyerahan bahan dan alat yang dibutuhkan pada masyarakat dalam upaya memelihara tanaman Casuarina di Pantai parupuk Tabing.

$\begin{array}{ccr}\text { Tim } & \text { pelaksana } & \text { bersama } \\ \text { masyarakat } & \text { melakukan } & \text { upaya }\end{array}$ pemeliharaan dengan meletakkan masingmasing bola-bola air di dekat batang tanaman tersebut. Tanaman tersebut sebelumnya diberi pupuk kandang sekitar 500 g per tanaman dengan menggali sekitar batang tanaman. Bola-bola air yang sudah diletakkan kemudian ditutup menggunakan sabut kelapa atau bahan lainnya, agar air terlindung dari teriknya panas matahari di siang hari. Upaya mengajak masyarakat dalam memelihara tanaman dilakukan dengan beberapa kali mediasi dan sosialsisasi di sekitar lokasi dan di masjid dekat lokasi kegiatan. Upaya ini berbuah dengan adanya penandatanganan nota kesefahaman antara masyarakat sekitar dengan tim untuk melakukan upaya pemeliharaan tanaman selanjutnya. Tanaman Casuarina diharapkan dapat bertahan hingga memberikan keteduhan dan menjadi fungsi penahan pantai dari ganasnya laut. Tanaman penghijauan tersebut juga memberikan dampak luas bagi masyarakat sekitar. Selama kegiatan pemeliharaan, masyarakat juga diedukasi dalam melakukan teknik pemeliharaan tanaman secara benar. Hal tersebut dikarenakan secara umum masyarakat adalah nelayan.

\section{HASIL DAN PEMBAHASAN}

Beberapa kali penghijauan yang dilakukan dengan usaha yang maksimal, telah memberikan kesegaran dan harapan baru bagi pantai yang gersang. Beberapa upaya yang dilakukan sehubungan dengan kegiatan penghijauan pantai adalah sosialisasi dengan masyarakat saat bulan Ramadhan, diawali dengan sholat tarawih bersama seperti pada gambar 2 .

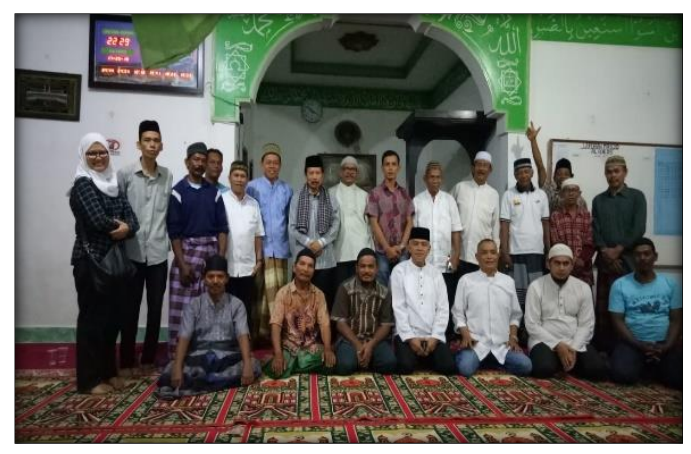

Gambar 2. Sosialisasi penghijauan pantai dengan tanaman Casuarina di Masjid Kelurahan Parupuk Tabing 
Selain kegiatan penanaman, juga dilakukan pemeliharaan dan penyulaman pada tanaman Casuarina yang mati. Beberapa tanaman yang sudah ditanam dijumpai sudah mati. Selain memang tidak dipelihara, juga akibat buruknya cuaca di pinggir pantai akibat gelombang tinggi pada bulan-nulan tertentu. Hal ini dapat dilihat dari tingkat abrasi yang sudah sangat mengkhawatirkan sampai ke lokasi tempat tumbuhnya Casuarina seperti Gambar 3. Oleh sebab itu, tindakan pemelihraaan tidak dapat ditunda agar pantai bisa terpelihara dari kuatnya deburan ombak.
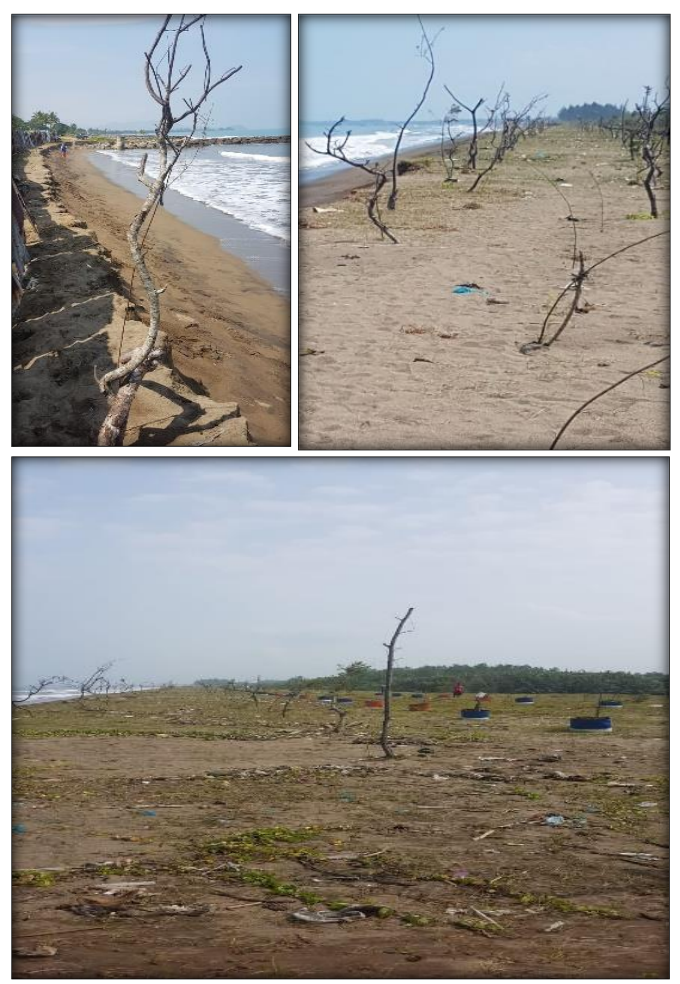

Gambar 3. Kondisi pantai yang sudah tergerus, dan banyak casuarina yang sudah mati karena kurangnya perawatan sebelum dilakukan kerjasama ini

Kuatnya badai sehingga membuat gelombang air laut mampu mencapai $2 \mathrm{~m}$, dan ini berdampak pada deburan ombak di tepi pantai. Jika dilihat pada Gambar 3, bahkan ada tanaman yang sudah hampir hanyut bersama deburan ombak, dan bibir pantai sudah hilang, terlihat pantai menjadi sedikit lebih curam dari sebelumnya. Oleh karena banyaknya tanaman Casuarina yang sangat bermasalah begitu dipindahkan ke tepi pantai, maka kerjasama dengan masyarakat dilakukan denga sepenuh hati. Perlu dilakukan komitmen bersama agar masyarakat juga terlibat dalam upaya pemeliharaan tanaman Casuarina tersebut. Oleh sebab itu dilakukan penandatanganan nota kesefahaman agar masyarakat memahami fungsi dan tugasnya sehingga tanaman Casuarina dapat terpelihara selama 3 bulan ke depan. Penandatangan nota kesefahaman tersebut disajikan pada Gambar 4.
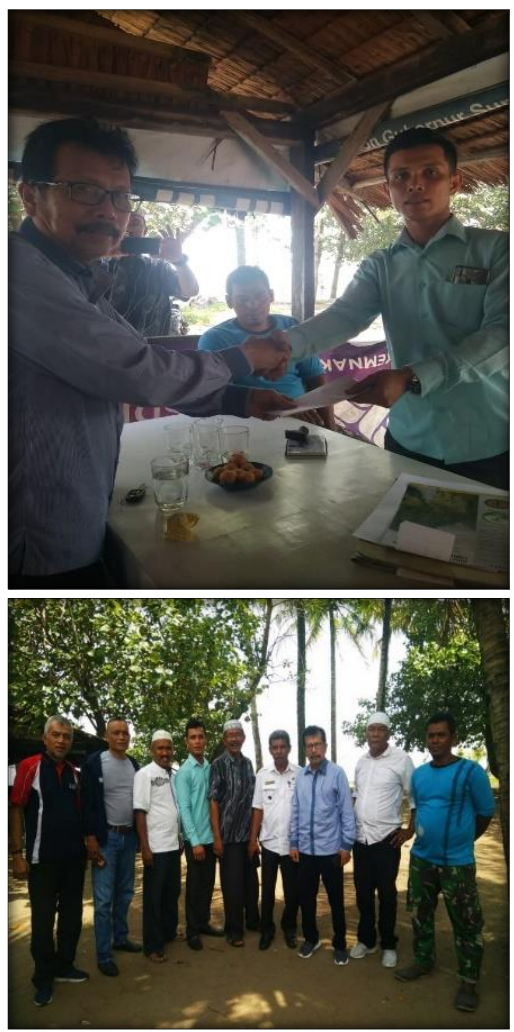

Gambar 4. Foto bersama masyarakat setelah penandatanganan MoU upaya pemeliharaan tanaman penghijauan pantai parupuk Tabing dengan tanaman Casuarina 
Pada kegiatan ini juga megajak masyarakat nelayan, kelompok pemuda, ketua Rukun Tetangga (RT) dan ketua Rukun Warga (RW) di Kelurahan Parupuk untuk diedukasi dalam pemeliharaan tanaman Casuarina agar dapat tumbuh sesuai standar minimal syarat tumbuh tanaman. Oleh karena tanaman ini masih dalam fase bibit, perlu perhatian serius untuk membuat tanaman tersebut dapat bertahan tumbuh di tepi pantai parupuk Tabing.oleh karena Casuarina merupakan yang memiliki kemampuan memfiksasi $\mathrm{N}$, maka ketahanan tanaman tersebut sangat dibantu oleh keberadaan bakteri yang tergolong Actinomycetes yaitu Frankia dalam membantu suplai Nitrogen ke tanaman inang. Frankia yang diisolasi dari tanaman Casuarina memiliki bakteri yang mengandung enzim Nitrogenase yang mampu memfiksasi N2 dari udara (Santos, et al., 2005) dan (Zhang, et al., 1984).

Bibit casuarina yang diinokulasi dan tidak diinokulasi dengan Frankia strain ORS021001 yang ditanam selama 4,5 bulan di polibag, kemudian ditranplantasi ke dalam pot besar ukuran volume $1 \mathrm{~m} 3$. Tanaman tersebut kemudian dipanen 6,5 bulan sehingga usianya menjadi 11 bulan. Fikasai N2 diukur menggunakan 3 metoda penilaian yaitu: the direct isotopic method, the A-value method, dan difference method. Perkiraan fiksasi N2 selama 6,5 bulan berkisar 3,27; 2,31; dan 3,07g N2 per pohon. Dari hasil perhitungan maka diperoleh bahwa ada sekitar 40-60 kg N2 difiksasi per hektar dalam 1 tahun dalam kondisi normal dengan kerapatan tanaman 10,000 batang ha-1. Frankia sebagai bakteri sebaiknya diinokulasikan ke tanaman Casuarina di lapangan (Gauthier et al. 1985; (Marlin, Yulian, \& M, 2010).

Pemeliharaan yang telah dilakukan oleh masyarakat Parupuk Tabing adalah dengan memasang tiang ajir atau stand tanaman sebanyak 2 buah agar tanaman tidak rebah karena angin kencang. Untuk mencegah kekeringan di setiap tegakan tanaman disiapkan bola-bola air yang sudah dilubangi kecil, dan dibiarkan hingga airnya cukup menetes saja. Ternyata hal ini cukup efektif karena tanah pasir yang sangat poreus tak dapat menahan air, bisa tersedia untuk tanaman melalui cadangan air tersebut. Pemanfaatan bola-bola air dengan menggunakan plastik ukuran $2 \mathrm{~kg}$, dapat bertahan hingga 1 minggu. Awalnya tanaman mati hingga mencapai 30\% maka dengan perlakuan tersebut mati hanya tinggal 5\% saja. Pada Gambar 5, tanaman sudah diberi penyangga stand sebanyak 2 buah, kemudian bagian akarnya diberi pupuk kandang agar kelembaban dan kesuburan tanah dapat tersedia bagi tanaman Casuarina tersebut. Pada Gambar tersebut kelihatan tanamannya tumbuh baik dan dapat bertahan dalam fase pertumbuhan selanjutnya. Dapat diyakini bahwa tanaman ini akan mampu bertahan lebih lanjut dan dapat menjadi tanaman yang diharapkan sebagai penahan pantai dari gangguan abrasi pantai oleh kuatnya gerusan ombak dan mitigasi bencana (Purwantara, Khotimah, \& Sudarsono, 2019). 


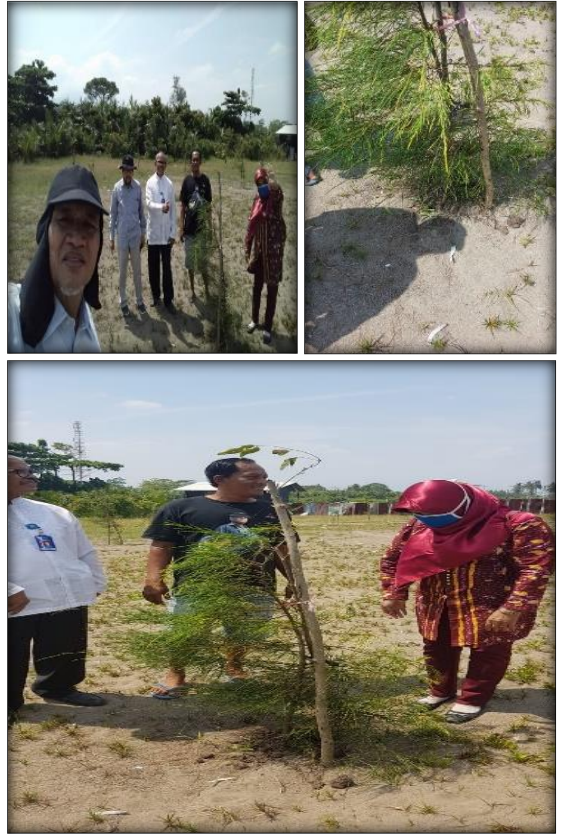

Gambar 5. Pertumbuhan Casuarina yang sudah optimal karena mendapat pemeliharaan yang intensif sesuai standar pantai.

\section{SIMPULAN}

Kegiatan penghijauan pantai Parupuk Tabing dengan menggunakan tanaman Casurina sangat efektif dalam memelihara pantai dari kekeringan dan kegersangan. Pemberian edukasi pada masyarakat nelayan di Pantai Parupuk Tabing dapat meningkatkan vitalitas pertumbuhan Casuarina yang akan memberikan pelindung pantai dari gerusan ombak laut.

\section{UCAPAN TERIMA KASIH}

Ucapan terima kasih kepada BPDASHL Agam Kuantan, Forum DAS Kota Padang yang telah memfasilitasi dan memberi bantuan dana untuk kegiatan pengabdian ini. Semoga Allah Taalla membalasnya dengan rezeki yang baik.

\section{DAFTAR PUSTAKA}

Anonim. 2013. Teknis Perbanyakan Tanaman Cemara Laut (Casuarina equisetifolia) Pada Media Pasir. Berita Dari Balai Besar Penelitian dan Pengambangan Bioteknologi Pemulilaan Tanaman Hutan. http://www.biotifor.or.id/content-196teknis-perbanyakan-tanaman-cemaralaut-casuarina-equisetifolia-padamedia-pasir.html, diakses tanggal 2 Juni 2020.

Gauthier D. H.G. DiemY.R. Dommergues F.Ganry. 1985. .Assessment of $\mathrm{N}_{2}$ fixation by Casuarina equisetifolia inoculated with Frankia ORS021001 using ${ }^{15} \mathrm{~N}$ methods. Soil Biology and Biochemistry. 17(3), 375-379.

Haryadi, B. 2015. Cemara Laut, Mengubah Pantai Berpasir yang Marginal menjadi Potensial. Berita Focus Litbang. Kementerian Lingkungan Hidup Dan Kehutanan. http://www.fordamof.org/index.php/berita/post/1999

John Aparrotta. 1999. Productivity, nutrient cycling, and succession in single- and mixed-species plantations of Casuarina equisetifolia, Eucalyptus robusta, and Leucaena leucocephala in Puerto Rico. Forest Ecology and Management. $\underline{124,(1), 45-77}$

MARLIN, YULIAN, BAMBANG GONGGO M . 2010. Kultur Immature-Embryo Cemara Laut (Casuarina equisetifolia) Pada Beberapa Konsentrasi Hara Makro Secara In Vitro. Laopran Penelitian dari Fakultas Pertanian Universitas Bengkulu.

https://core.ac.uk/download/pdf/353 35560.pdf 
Marlin, Yulian, \& M, B. G. (2010). Casuarina equisetifolia). Fakultas Pertanian Universitas Bengkulu, 1.

Nugroho, A. W., \& Sumardi. (2010). Ameliorasi tapak untuk pemapanan cemara udang (Casuarina equisetifolia Linn) Pada Gumuk Pasir Pantai. Jurnal Penelitian Hutan Dan Konservasi Alam, 7(4), 381-398.

Ogunwande, I. A., Flamini, G., Adefuye, A. E., Lawal, N. O., Moradeyo, S., \& Avoseh, N. O. (2011). Chemical compositions of Casuarina equisetifolia L ., Eucalyptus toreliana L . and Ficus elastica Roxb . ex Hornem cultivated in Nigeria. South African Journal of Botany, 77(3), 645-649.

https://doi.org/10.1016/j.sajb.2011.02 .001

Purwantara, S., Khotimah, N., \& Sudarsono, A. (2019). Persepsi Maysarkat Terhadap penanaman Cemara Laut (Casuarina equisetifolia) di Lahan Pasir Pantai Selatan Kabupaten Bantul Sebagai Upaya Mitigasi Bencana. Geomedia Majalah Ilmiah Dan Informasi Kegeografian, 17(2), 99-106.

Santos, P. E. L., Jose, J., Normand, P., \& Hirsch, A. M. (2005). Non- Frankia Actinomycetes Isolated from SurfaceSterilized Roots of Casuarina equisetifolia Fix Nitrogen $\uparrow$. Applied and Enviromental Microbiology, 71(1), 460-466. https://doi.org/10.1128/AEM.71.1.46 0

Zhang, Z., Lopez, M. F., \& Torrey, J. G. (1984). A comparison of cultural characteristics and infectivity of Frankia isolates from root nodules of Casuarina species. Plant and Soil, 90(78), 79-80. 